\title{
Monitoring and Control System for Seed Germination Using Internet of Things
}

\author{
Deisiane Santos da Cruz ${ }^{1}$, Caio Castro Rodrigues', João Vitor Natal Silva Quincó \\ Maciel $^{2}$, Nilcilene Branquinho da Silva ${ }^{2}$, Demora Gomes de Araújo ${ }^{2}$, Otavio Andre \\ Chase $^{1}$, José Felipe de Almeida ${ }^{1}$ \\ ${ }^{1}$ Instituto de Cibespacial - Universidade Federal Rural da Amazônia (UFRA) \\ CEP 66.077-83 - Belém - PA - Brazil \\ ${ }^{2}$ Departamento de Engenharia de Controle e Automação - Universidade Estácio de Sá \\ CEP 66.055-260 - Belém - PA - Brazil \\ \{deisecruz10, caiocastro.eng, joaoquinco.eng,nilci.eng\} @gamil.com, \\ \{denmora.araujo, otavio.chase, felipe.almeida\} @ufra.edu.br
}

\begin{abstract}
This article presents an architecture of a reduced-size greenhouse, so-called mini-greenhouse monitored via Internet of Things (IoT). For this purpose, a prototype has been built with support of a computational system installed in its interior. So, sensors are used for monitoring and control of the variables that most influence in the development of a vegetal species. This text gives a brief description of the germination factors related on the various possibilities of its use. The proposed system has a cloud-based storage and the effective contributions of the computer system are started from the web platform, transfer the set-points to the controllers, and upload data read from sensors to the same web page.
\end{abstract}

\section{Introduction}

The technology of the Industrial Revolution 4.0, which emerges in today's world is known as the Internet of Things or IoT [Chase et al. 2018]. Among its benefits are mainly the optimization, control and automation of processes, previously done manually [Greengard 2015].

Light in seed germination plays a predominant role in the Phytochromatic pigment system, which is responsible for the perception of the luminosity in the plants. These pigments are found in all higher plants, and when they absorb certain wavelengths within the light range, they become active, acting as if they were an enzyme [Borges and Rena 1993; Menezes 2004]. Thus, the effect of light on the embryo allows the radicle, embryonic root, to penetrate the endosperm, thus, occurring the germination [Taiz et al. 2017]. Another important factor in germination is temperature, responsible for the speed and uniformity of emergence of seedlings [Carvalho and Nakagawa 2000; Guedes 2010]. The effect of temperature is mainly present in the absorption of water and in the biochemical processes that will act on its energy reserves [Bewley and Black 1994; Demuner 2008]. As a result, it is essential to control these two variables, i.e., temperature and brightness, so that more uniform germination occurs in optimized time.

This work deals with the development of a computational system, with a view to applications in a mini vegetation house. For this, a prototype of a mini-greenhouse was 
built, and the implementation of the embedded system is made using sensors capable of in vitro verification of the conditions suitable for the germination and growth phase of plant species [Makishima and Carrijo 1998]. From this monitored environment, a database is generated, with cloud storage of computers and the records of the obtained data are made available in real time with computer access through Internet or network for mobile devices. Thus, the objective of this study is to present the development of a system model embedded in IoT communication, with a function of access to information records on irrigation, temperature, humidity and with indoor lighting, in addition to other sensors, in the monitoring and control related to germination processes.

\section{Materials and Methods}

The current project considers an embedded computer system that has been developed capable of collecting environmental data by sensors and storing them in the cloud (digital cloud). This process is facilitated through the IoT communication, which was built primarily to monitor and control all events involved in a greenhouse and the data are obtained in short time intervals without the need for manual recording. Processing and data acquisition are performed on the Raspberry Pi 3 card (controller) programmed in Python 3. This card has a network module (WiFi) integrated into its internal circuit and a $1.2 \mathrm{GHz}$ 64-bit quad-core processor with $1 \mathrm{~GB}$ of memory, because these characteristics favor the response time of the program when performing data upload with the cloud. The ThingSpeak ${ }^{\mathrm{TM}}$ platform was chosen because it is a tool for IoT data acquisition and analysis with reliability and security.

The developed system can collect data through sensors related to temperature and relative humidity (DHT22), luminosity (BH1750), temperature (DS18B20) and soil moisture (Hygrometer). The DHT22 module is a digital measuring device, consisting of a capacitive sensor for the measurement of relative humidity, with an accuracy of $\pm 2 \%$ $\mathrm{RH}$, and a thermistor for temperature measurement, with an accuracy of $\pm 0,5^{\circ} \mathrm{C}$ - both measurements with resolution of 0.1 and response time of $2 \mathrm{~s}$. This information together with incident light data is very important for the biochemical development of plants. The BH1750 light sensor uses I2C communication interface and 16-bit AD converter, making possible to measure from 1 to $65,535 \mathrm{~lx}$, with a resolution of $0.5 \mathrm{~lx}$ when set to operate at intervals over $120 \mathrm{~ms}$. These devices function as a feedback signal for the controller to process and send the control signal, which is responsible for the activation of an incandescent lamp - 60W of power was used as the source of light and heat. Also, for a specific purpose in experiments it is necessary to maintain luminosity without significant change in temperature, LED tapes can be used $-15 \mathrm{~W}$ was used as light source. A cooler was also used to soften the effects of temperature and humidity, with the renewal of the air inside the prototype of the mini greenhouse. Figure 1 shows the sensors and actuators used in Prototype 

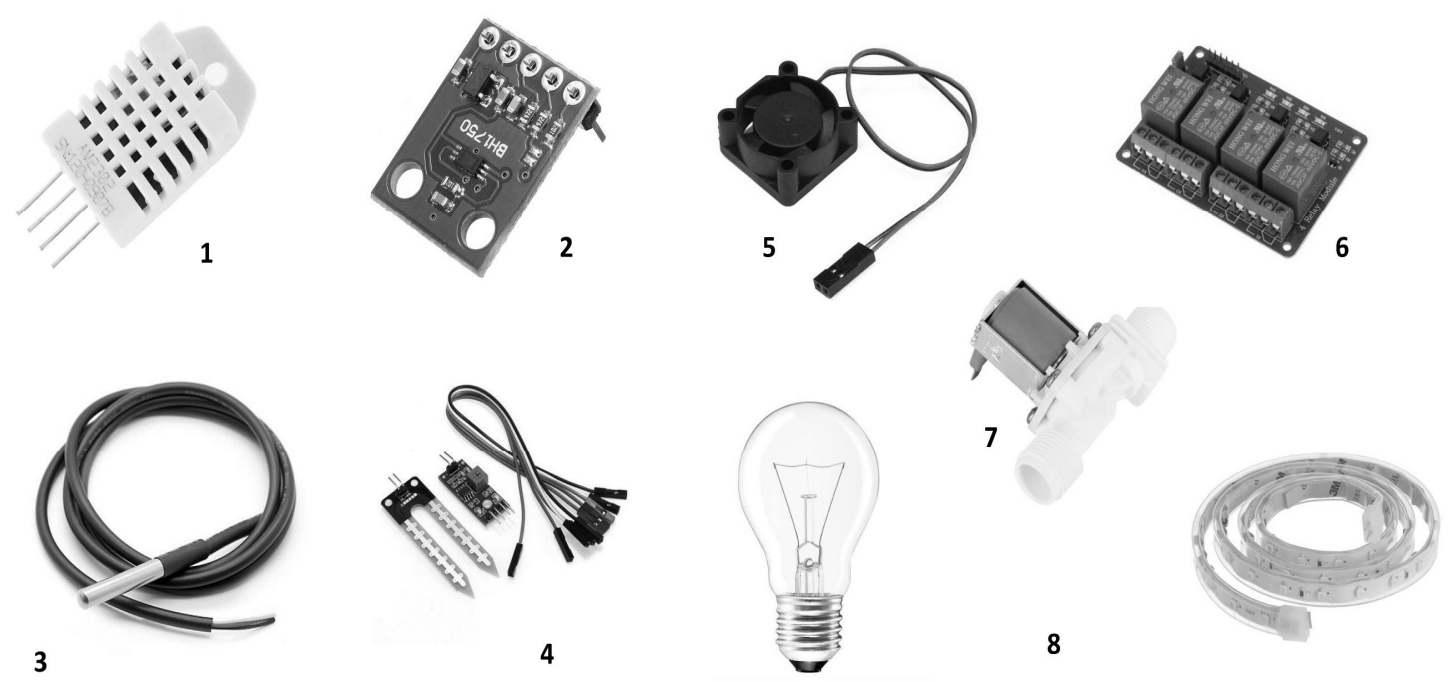

Figure 1. Sensors: 1-DTH22; 2- Light sensor; 3-Temperature sensor; soil moisture sensor. Actuators: 5-Cooler; 6- 4-channel relay module; 7-Solenoid valve 12 VDC; 8- Lamp and LED strip

Soil temperature is another important data and, in this prototype, the DS18B20 module was used, so that it is a very precise sensor $\left( \pm 0.5^{\circ} \mathrm{C}\right)$ for the proposed application, since its operating range $\left(-10^{\circ} \mathrm{C}\right.$ to $\left.85^{\circ} \mathrm{C}\right)$ meets this need. It is noteworthy that this device uses OneWire libraries for address and port saving of the controller. In this sense, the soil moisture is obtained through the electrical conductivity. Inasmuch as this sensor has two parallel metal rods and when an electric current is applied to one of the sensor rods in the form of an electrode, it propagates through the ground to the other rod that is sensitive to voltage variation. Consequently, it is possible to determine the percentage of water in the soil in relation to a reference measure. Thus, from a certain value of humidity, inserted in the programming of the control board, a solenoid valve is activated to perform the irrigation automatically.

Finally, the mini-house was built with a wooden structure, whose dimensions are $40 \times 50 \times 40 \mathrm{~cm}$ and glass on its side faces.

\section{Results and Discussion}

In this project, the proposed system was developed with the architecture of a mini greenhouse and the same characteristics of a chamber of type B.O.D. (Biochemical Oxygen Demand). Linked to this prototype, a computer system was shipped with communication via IoT, using the ThingSpeak ${ }^{\mathrm{TM}}$ platform. After installation of the sensors and actuators, these devices were calibrated according to information suggested by the manufacturers. Figure 2 shows the prototype of the mini-greenhouse and includes sensors for monitoring and actuators related to the control of conditions that may favor the study of seed germination. 


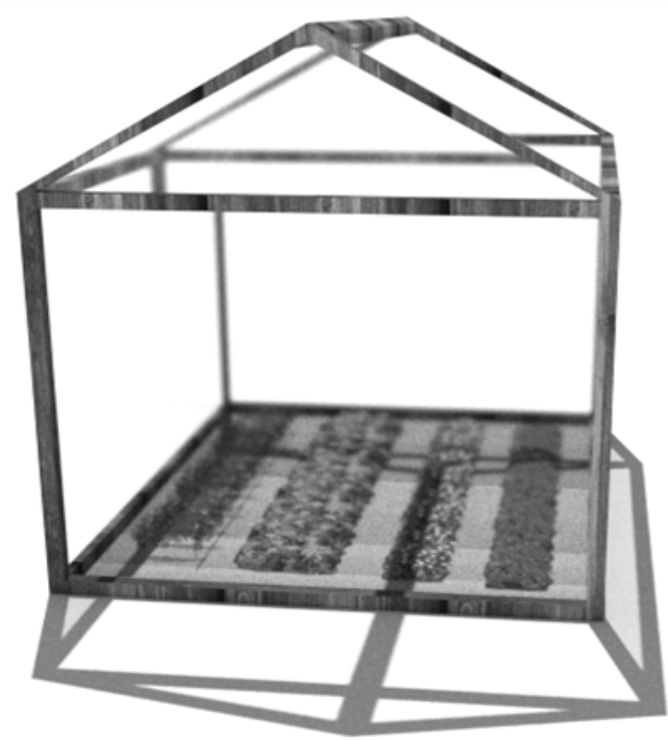

Figure 2. The prototype of a mini-greenhouse

Germination is a process by which the seeds re-perform their metabolic activities from the embryonic axis, thereby emitting their root system [Oliveira et al. 2011]. This biophysical process is regulated by an interaction between its physiological state and environmental conditions, such as temperature and light [Mayink and Mayak 1989; Mondo 2010]. In this way, the system was activated, and the tests were performed, to obtain control about these data. Firstly, the data acquisition was tested by the microcontroller along with IoT communication on the ThingSpeak ${ }^{\mathrm{TM}}$ platform. Figure 3 shows the data measured inside the prototype of Figure 2.
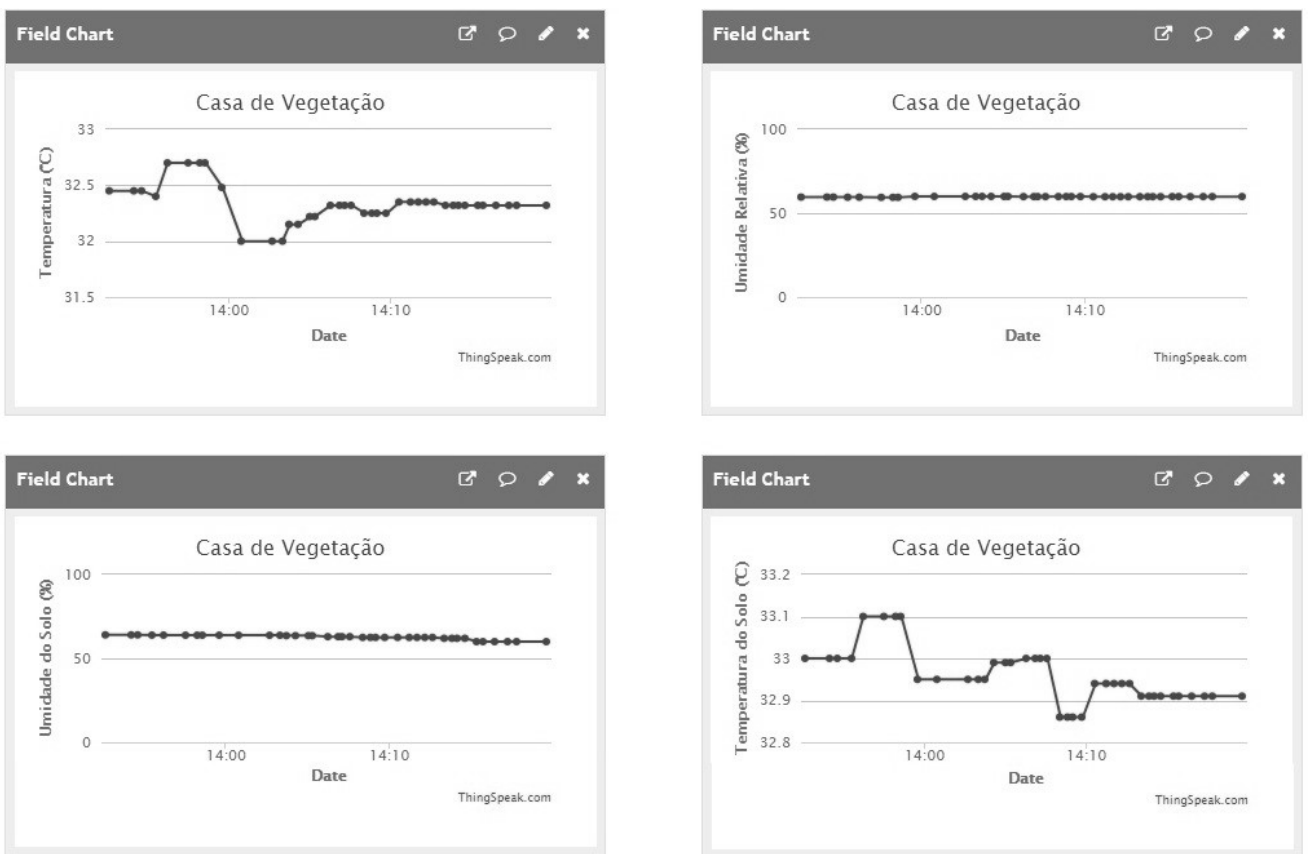

Figure 3. Temperature records, Relative Air Humidity, Soil Moisture and Soil Temperature, inside at mini-greenhouse via ThingSpeak ${ }^{\mathrm{TM}}$ 
The data related to temperature and soil moisture were collected from a gear box placed inside the prototype with conditions said to be ideal. Soon afterwards another gear box was placed with different humidity conditions of the first and, in this way, the system managed to moisten the container through a solenoid valve. According to preestablished conditions.

Regarding the luminosity, the prototype was connected in a place with 31x of natural luminous incidence. When the internal lighting (incandescent lamp and LED strips) were connected, an increase of $981 \mathrm{~lx}$ was observed in the incidence of the light sensor. However, this maximum incidence value within the mini greenhouse may be changed, depending on external light interference. Another important feature to note is the fact that the air temperature control varies further with the lamp on or return to the ambient temperature due to the presence of a cooler. In this way, it was possible to carry out the control, observing that it was only possible to reach a maximum value of air temperature around $58^{\circ} \mathrm{C}$ when the ambient temperature was $26^{\circ} \mathrm{C}$ on average.

Considering the limitations of the sensors in response time, processing time of Raspberry Pi 3 and communication by digital cloud, the sampling time of the system was $30 \mathrm{~s}$ - with the internet connection stable and with average connection speed established at $12 \mathrm{Mb} / \mathrm{s}$. In fact, remote access to data is not yet widespread in the means of production, but it can already provide detailed information on the development of the plant in relation to the environment in which it is exposed. And, with this system, we can maintain the control of the seed germination phase, obtaining, therefore, the information of its main characteristics of growth.

\section{Conclusions}

This work dealt with a mini-greenhouse architecture, using sensors and access via IoT. Regarding the applicability of this architecture, there are the control and monitoring of the variables corresponding to the morphometry of structures that may be present for analysis. However, due to the objective of this proposal, the tests in cultures were not presented, but the system was implemented to evaluate this type of product. As a result, embedded system devices and real-time graphical obtained by using IoT platform in cloud computing were shown. It is worth mentioning that the computational module has several advantages over conventional B.O.D., which are well known in these procedures related to seed germination, as an example: low cost; the control of irrigation, luminosity and temperature; and access the information in real time. The major advantage of this tool is that uses open source software and generic hardware in which the system allows insertion of new sensors, as is the case of $\mathrm{CO} 2$ measurements, ultraviolet radiation, among others.

\section{References}

Bewley J. D., Black M. (1994). Seeds: physiology of development and germination. Plenum Press, New York, 445 p.

Borges E. E. L., Rena A. B. (1993). Seed Germinations. In: Aguiar I. B., PinãRodrigues F. C. M., Figliolia M. B. (Editors.). Tropical Forestry Seeds. Brasília: ABRATES, 1993. p.83-135 
Chase O. A., Carvalho A. N., Andrade E. S. S. (2018). Costa Junior C. T.; Almeida J. F. Environmental Measurement Technology: an approach to the Amazonian environment. IEEE Latin America Transactions, 16(4):1036-1041. https://doi: 10.1109 / TLA.2018.8362134.

Demuner V. G., Adami C., Mauri J. (2008). The Influence of Light and Temperature on Seed Germination of Erythrina verna (Leguminosae, Papilionoideae) Boletim do Museu de Biologia Mello Leitão, 24:101-110.

Greengard, S. The Internet of Things. (2015). The MIT Press Essential Knowledge Series. Ed.1. Versão Kindle. Cambridge, Massachusetts. The MIT Press.

Guedes, R. S., Alves, E. U., Gonçalves, E. P., Braga J. M. J., Viana J. S., Colares P. N. Q. (2010). Substrates and Temperatures for Germination and Seed Vigor Tests of Amburana cearensis (Allemão) A.C. Smith. Revista Árvore, 34(1):57-64.

Makishima N., Carrijo O. A. (1998). Protected Tomato Cultivation. Embrapa Technical Circular Greens 13.

Mayer A. C., Poljakoff Mayber A. (1989). The Germination of Seeds. 4.ed. Oxford: Pergamon Press.

Mando V. H. V., Carvalho S. J. P., Dias A. C. R.; Marcos Filho J. (2010). Effects of Light and Temperature on Seed Germination of Four Species of Weed Plants of the Digitaria Genus. Brazilian Journal of Seeds, 32(1):131-137.

Menezes N. L., Franzin S. M., Roversi T., Nunes E. P. (2004). Germination of Seeds of Salvia splendens Sellow in Different Temperatures and Qualities of Light. Brazilian Seed Journal, 26(1):32-37.

Oliveira A. K. M., Ribeiro J. W. F, Perreira K. C. L, Silva A. A. S. (2011). Seed Germination of Aspidosperma tomentosum Mart. (Apocynaceae) at Different Temperatures. Brazilian Journal of Biosciences, http://www.ufgs.br/seerbio/ojs/ index.php/article/vive/1857

Popinigis, F. (1985). Physiology of Seed. Brasília: AGIPLAN, 289p.

Taiz, L., Zeiger E., Møller I. M., Murphy A. (2017). Physiology and Plant Development. Porto Alegre: Artmed, ISBN 978-85-8271-367-9. 